\title{
TESTING COEXISTENCE OF EXTINCTION DEBT AND COLONIZATION CREDIT IN FRAGMENTED CALCAREOUS GRASSLANDS WITH COMPLEX HISTORICAL DYNAMICS
}

Julien Piqueray ${ }^{1}$, Sara Cristofoli ${ }^{1}$ Emmanuelle Bisteau ${ }^{1}$, Rodolphe Palm², Grégory Mahy'.

${ }^{1}$ University of Liege, Gembloux Agro-Bio Tech, Laboratory of Ecology. 2, Passage des Déportés B-5030 Gembloux. Belgium.

'University of Liege, Gembloux Agro-Bio Tech, Department of Applied Statistics and Mathematics. 2, Passage des Déportés B-5030 Gembloux. Belgium.

Landscape Ecology, accepted. DOI: 10.1007/s10980-011-9611-5

The final publication is available at www.springerlink.com 


\begin{abstract}
Calcareous grasslands are among the most species-rich ecosystems in temperate countries. However, these ecosystems have suffered from fragmentation and destruction during the last century. We studied the response of calcareous grassland plant diversity to landscape changes in Belgium. Results indicated that high area loss (since 1965) old habitat patches exhibited an extinction debt inverse to low area loss old habitat patches, little depending on the area loss threshold $(60 \%, 70 \%, 80 \%$ or $90 \%)$ considered for the distinction between the high and low area loss patches. However, human activities also created new habitat patches in the landscape and therefore provided opportunities for calcareous grassland plant species to colonize new habitats. This also provided opportunities to study species colonization abilities in the context of habitat restoration. We analyzed species richness in new patches compared to old patches in order to detect colonization credit. We detected the presence of a colonization credit in new patches when using high loss old patches (area loss $>00 \%$, exhibiting an extinction debt) or all old patches as a reference. However, when the reference was low loss old patches alone (area loss $880 \%$, less likely to exhibit an extinction debt), no colonization credit was detected. In addition, species composition was similar between new patches and old patches. These results are encouraging for restoration programs. However, the results indicated that the presence of an extinction debt in reference habitats could lead to inaccurate conclusions in restoration monitoring. Therefore, extinction debt should be considered when choosing reference habitats to evaluate restoration success.
\end{abstract}

Keywords: Belgium, Calcareous grassland, Colonization credit, Extinction debt, Vascular plants 


\section{Introduction}

The last decades have been increasingly dominated by a shift in ecology from an equilibrium paradigm to a non equilibrium paradigm (Holling 1973; Perry 2002; Turner 2010). This shift was fueled with the development of landscape ecology and the recognition of the role of disturbances and chance events in dynamics of ecological systems (Perry 2002). Although empirical studies suggest that it may be rare for a landscape to be at equilibrium (Perry 2002), landscape ecology has been largely dominated by the quest for equilibrium relationships when dealing with biodiversity. This is well illustrated by the use of relationship between species richness and habitat area or connectivity, issued from the equilibrium theory of insular biogeography, to devise conservation approaches at the landscape and habitat scale (Saunders et al. 1991; Turner et al. 2001; Ricklefs 2004; Laurance 2008).

However, anthropogenic activities have greatly modified disturbance regimes and are currently the primary drivers of landscape and consequently biodiversity dynamics (Baudry \& Tatoni 1993; Jongman 2002). Recently, disequilibrium situations in landscapes have received particular attention in ecological studies at the landscape level (Cousins 2009; Kuussaari et al. 2009). Human-driven landscapes are characterized by destruction and fragmentation of (semiInatural habitats (Saunders et al. 1991). Landscape dynamics mediated by human activities may also result in the origin of new habitat patches with conditions conducive to spontaneous colonization by species from natural or semi-natural habitats (Krüger et al. 2002; Bizoux et al. 2004; Faucon et al. 2009). Habitat patch fragmentation and creation dynamics may be a rapid process (Adriaens et al. 2006). In contrast, species response to environmental change can be slow and a time lag can therefore exist between these processes. As a consequence, dynamic communities that experience habitat destruction and/or creation of new habitat patches may face two disequilibrium situations with regard to patch spatial characteristics. First, following decrease in habitat area and connectivity, an extinction threshold (sensu Kuussaari et al. 2009) can be reached for several species. However, extinction may be delayed resulting in the creation of an extinction debt in fragmented habitats (Hanski \& Ovaskainen 2002; Jackson \& Sax 2009; Kuussaari et al. 2009). One consequence of extinction debt is the occurrence of a time lag during which species richness of habitats is higher than expected by their area and connectivity. Second, a colonization credit (Cristofoli \& Mahy 2010; Cristofoli et al. 2010b) may occur during the time needed for all eventual immigration to occur (Jackson \& Sax 2009; Kuussaari et al. 2009: Cristofoli et al. 2010b). During that time, new patches would exhibit a species richness lower than expected by the area and connectivity characteristics.

Extinction debt and colonization credit are important components for devising biodiversity conservation and habitat restoration strategy. The identification of an extinction debt in a given landscape indicates that some species are deterministically fated to go extinct, as current landscape structure does not permit their long-term survival. As a consequence, the restoration 
of habitat networks permitting long-term survival of habitat specialist species has become an important goal, and understanding colonization dynamics and processes is a critical component of those efforts (Jongman \& Pungetti 2004). Studies aiming at quantifying colonization credit provide information regarding species colonization ability following the creation of new habitat patches (Cristofoli \& Mahy 2010; Cristofoli et al. 2010b). However, an estimate of colonization credit may be challenged when the fragmentation of historical habitats occurs concurrently with the creation of new habitat patches in a landscape (Cristofoli et al. 2010b). The potential cooccurrence of extinction debt and colonization credit in a landscape makes it necessary to determine how the presence of an extinction debt in reference habitat may influence the results of colonization credit studies and how to differentiate both conditions when they co-occur (Cristofoli et al. 2010b).

Semi-natural calcareous grasslands rank as one of the most species-rich among temperate plant communities and are considered local biodiversity hotspots (Prendergast et al. 1993; WallisDeVries et al. 2002). In Belgium, as in many parts of Europe, these habitats suffered extensive effects of fragmentation processes in the past due to abandonment of the traditional agro-pastoral system and resulting encroachment of grasslands, afforestation, urbanization and transformation into arable lands (Poschlod \& WallisDeVries 2002; Adriaens et al. 2006). In other respects, some human activities (e.g. road verge creation, quarry abandonment, and forest clearings) may unintentionally provide colonization opportunities for calcareous grassland species. As a consequence of these landscape dynamics, communities hosted by calcareous grasslands may be confronted with unbalanced states resulting from an extinction debt (Lindborg \& Eriksson 2004; Adriaens et al. 2006; Helm et al. 2006; Lindborg 2007) or a colonization credit. Ambitious calcareous grassland restoration projects have emerged in Europe over the last 15 years (Kiefer \& Poschlod 1996; Pärtel et al. 1998; Kiehl et al. 2006; Fagan et al. 2008; Piqueray et al. 2011a). Most restoration programs are rather recent and little can be determined regarding the longterm effects of restoration. However, habitat patches created in the last few to several decades and for which history may be well documented are ideal systems to evaluate the probability of colonization in a temporal framework suitable for ecological restoration projects.

The aim of this study was to investigate and assess the consequences of habitat fragmentation and habitat creation on calcareous grassland plant species richness in Belgium. We made a survey of calcareous grassland spatial and temporal landscape change over approximately 100 years, highlighting both habitat destruction and creation under a global fragmentation pattern. We asked 1) whether fragmented habitat patches harbor an extinction debt; 2) whether newly created patches (since 1965) harbor a colonization credit; and, 3) whether the presence of an extinction debt in reference habitats may influence estimates of colonization credit. 


\section{Methodology}

\section{Study site}

The study site (approximately $25 \mathrm{~km}^{2}$ ) is located in the Lesse Valley, in southern Belgium $\left(50^{\circ} 05^{\prime}\right.$ to $50^{\circ} 09^{\prime} \mathrm{N} ; 5^{\circ} 06^{\prime}$ to $5^{\circ} 15^{\prime} \mathrm{E}$; alt. 150 to $250 \mathrm{~m}$ ) (Fig. 1). Calcareous grasslands were developed under traditional agro-pastoral practices on Devonian limestone hills and plateaus. Due to abandonment of traditional agriculture in the $19^{\text {th }}$ century, calcareous grasslands have declined dramatically in the region (Bisteau \& Mahy 2005; Adriaens et al. 2006). During the time range covered by this study (1920-2002), little management occurred in calcareous grasslands in the study site. Only few patches had conservative grazing from the end of the 1990's. Therefore, management during the last century did not have a strong influence in species richness and composition. Semi-natural calcareous grasslands are presently located in small welldelimited patches surrounded by forests and improved meadows or arable lands. Although highly fragmented, the region supports one of the last significant areas of calcareous grasslands in Belgium. 

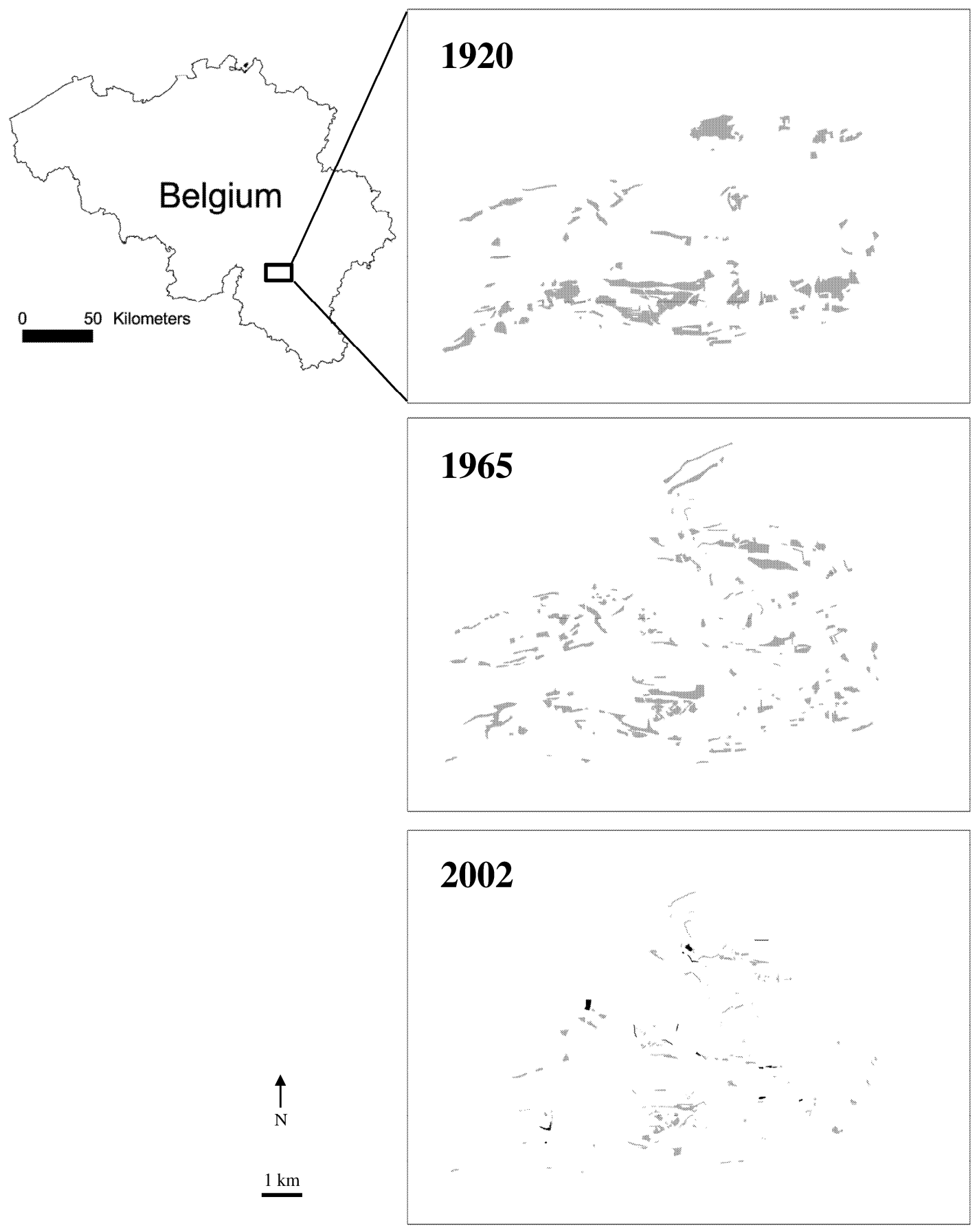

Fig. 1: Study site location in Belgium and calcareous grassland network at three time periods. Latitude-longitude range: $50^{\circ} 05^{\prime}$ to $50^{\circ} 09^{\prime} \mathrm{N} ; 5^{\circ} 06^{\prime}$ to $5^{\circ} 15^{\prime} \mathrm{E}$. New patches considered in analyses are in black in the 2002 frame. 


\section{Landscape dynamics and species data}

Calcareous grassland patches located in the study site were digitised in a GIS database (ArcView 3.2, ESRI 2000) derived from recent aerial photographs and field surveys in 2002. Past calcareous grassland landscape configuration was reconstructed using historical detailed topographical maps for 1920 (Institut Royal Militaire de Belgique (IRMB), scale 1:20000) and 1965 (Belgian National Geographic Institute (BNGI), scale 1:10000) and 1965 aerial photographs (Belgian National Geographic Institute (BNGI), scale 1:20000). The 1920 period corresponds to the end of shepherding and the onset of a rapid decline of calcareous grasslands in Belgium (Delescaille 2002). Cartographic documents for 1920 and 1965 periods were relatively comparable as military maps served as basis for the creation of the BNGI 1965 topographic maps. The legend of these maps provides a category "heathlands and common pastures", which, in addition to topography and geology, permit confident identification of calcareous grasslands. However, uncertainties on the location of grasslands were greater for 1920 as no aerial pictures were available to validate cartographic documents. Current and historical patch areas were directly derived from the GIS. Current and historical patch connectivity was estimated using the IFM index derived from Hanski (1994), using edge-to-edge distances among all patches. The metric applies distances to (no multiplication factor was used for distance) and area of all possible source populations in the landscape (Moilanen \& Nieminen 2002) as follows:

$$
\text { IFMi }=\sum A j^{*} e^{-d i j}
$$

where IFMi is the connectivity of the ith patch, $A j$ is the area of the jth patch, dij is the distance between the ith and the jth patch.

Presence-absence data of all vascular plant species were recorded in each calcareous

grassland patch during spring and summer 2002 and 2003. Calcareous grassland specialist species were identified on the basis of a classification of local grassland communities (Piqueray et al. 2007). We subsequently estimated for each grassland patch the total species richness $\left(S_{\text {tot }}\right)$ and the specialist species richness $\left(S_{s p}\right)$. Species nomenclature followed Lambinon et al. (2004).

\section{Extinction debt and colonization credit estimates}

To estimate extinction debt and colonization credit, we first distinguished two groups of calcareous grassland patches on the basis of the characterization of landscape dynamic: 1) old patches, i.e., grassland patches present in all cartographic data (1920, 1965 and 2002); 2) new patches, i.e., patches created after 1965 that are likely to exhibit a colonization credit. 


\section{EXTINCTION DEBTESTIMATE}

Extinction debt was estimated within old patches using a method inspired from Helm et al. (2006). The method compared the relationships between current patch spatial metrics and current species richness for two groups of old patches that differ in their rate of area loss since 1965: low loss old patches and high loss old patches. Current patch area was selected as the spatial metric covariable for the analysis given its prominent effect on species richness (Table 1). Low loss old patches (designated as "low loss patches") represent the most stable patches in the landscape over time. Because these patches have changed relatively little in area since at least 1965, we postulate they provide the closest to equilibrium for relationships between area and species richness. High loss old patches (designated as "high loss patches") represent patches that have undergone a higher rate of area loss in the landscape over time. Due to their high fragmentation, these patches are more prone to exhibit an extinction debt, i.e. observed species richness would be higher than expected at equilibrium with the spatial configuration of the patch.

Four area lost thresholds $(60 \%, 70 \%, 80 \%, 90 \%$ lost) were considered to distinguish low loss and high loss patches, and independent analyses were computed for each threshold. $A$ comparison of species richness between two groups of patches (low loss - high loss) was computed using ANCOVA. Prior to the analysis, different transformations on species richness ( $S_{\text {tot }}$ and $S_{s p}$, independent variable) and area (covariate) were tested in order to improve normality and homoscedasticity of residuals using a Minitab macro (Palm 2002). Furthermore, only patches that covered approximately the same range of current area in both low loss and high loss patches were retained. In ANCOVA analysis, significant interaction between current area and the classification variable (high loss, low loss) would indicate that species richness responds differently to current area for the two groups of patches. The interaction effect is further named "parallelism test". Extinction debt was tested as the significance of the global species richness difference between the two groups of patches considering area as a covariable. Analyses were independently computed for total and specialist species richness. Extinction debt was not estimated in relation to the landscape spatial configuration in 1920 because we wanted the analysis to be comparable to estimation of credit colonization credit (see next section).

\section{COLONIZATION CREDITESTIMATE}

Colonization credit was estimated using the same method as extinction debt. In this case, the method compared species richness between new patches and different kinds of reference old patches, using area as a covariable. New patches are patches created after 1965. Due to their recent creation, they may exhibit a colonization credit, i.e. observed species richness is lower than expected at equilibrium with the spatial configuration of the patch. We recorded whether those patches originate from conversion of arable fields, clearing in forests or creation 
of new road verges. We did not use the 1920 reference for delimitation of new patches due to the uncertainty of cartographic information (see results). Colonization credit was estimated for three conditions (i.e. using three kinds of reference old patches): 1) Comparisons between "new patches" and "low loss old patches" (patches that are unlikely to exhibit an extinction debt); 2) comparisons between "new patches" and "high loss old patches" (patches that are likely to exhibit an extinction debt); 3) comparisons between "new patches" and all old patches ("low loss old patches" and "high loss old patches") (patches that may exhibit different levels of extinction debt).

Not all the thresholds considered in the extinction debt analysis for the distinction between "low loss old patches" and "high loss old patches" were considered in the colonization credit analysis. Given that the main aim of this analysis was to elucidate the effect of the occurrence of an extinction debt on colonization credit estimates, we only considered the threshold for which the evidence of an extinction debt was the strongest.

In order to detect the influence of the new patches origin (conversion of arable fields, clearing in forests or creation of new road verges), we used ANOVA to test for differences in patch colonization credit (e.g. difference between species richness predicted by reference model and observed species richness) between patches with different origins, considering "low loss patches" as reference.

Species richness may result from different species composition in the communities, therefore plant assemblages were compared among new patches and old patches using detrended correspondence analyses in CANOCO 4.5 (ter Braak \& Smilauer 2002). Two independent analyses were computed for total and specialist species. We also tested if some specialist species had a lower relative occurrence in new patches than in old patches using a Fischer exact test. ANCOVA and Fischer exact tests were performed using Minitab 15 (Minitab, Inc.).

\section{Results}

\section{Spatio-temporal dynamics of calcareous grasslands}

Calcareous grasslands experienced severe fragmentation over the last 80 years in the study area (Figs. 1 and 2). From 1920 to 2002, the total area of calcareous grasslands was reduced by $87 \%$. However, over the same time period, the number of calcareous grassland patches increased two-fold. Increase in patch number was due to both splitting of large patches and creation of new patches (Fig. 2). Patch mean area decreased by $93 \%$ (1920: mean=4.7ha, $S D=8.9$ ha; 2002: mean $=0.31 \mathrm{ha}, S D=0.59 \mathrm{ha}$ ). Connectivity decreased both between 1920 and 1965 and between 1965 and 2002. The fragmentation process between 1920 and 1965 was evidenced by an increase in the number of patches (approximately two-fold), and a limited loss in total area (21\%). The fragmentation process between 1965 and 2002 was characterized by a decrease in 
patch area (83\% total area loss; $83 \%$ mean patch area decrease), while the number of patches remained relatively stable.

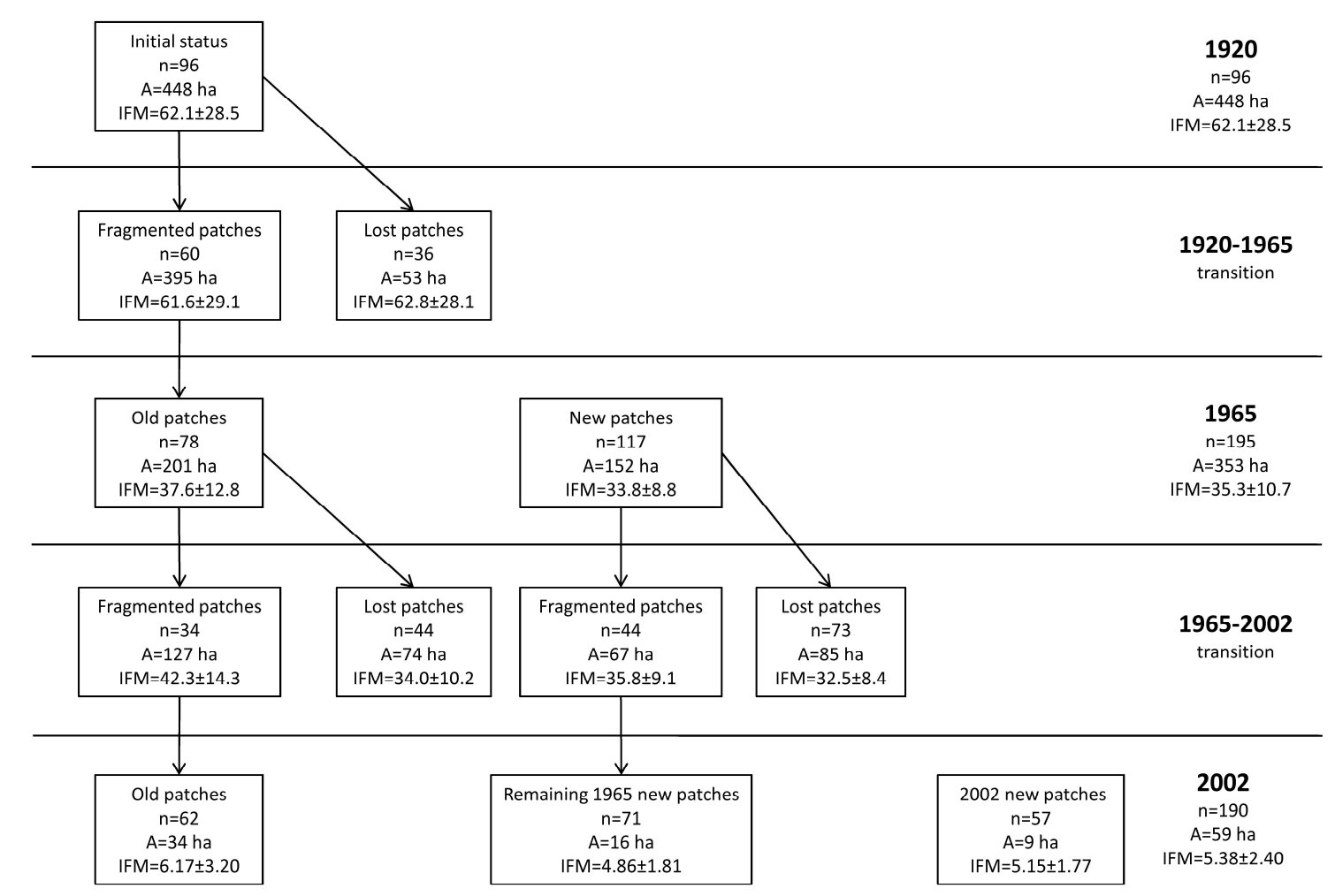

Fig. 2: Calcareous grassland patch dynamics at the study site. $n$ is the number of patches, $A$ is the total area, IFM is the connectivity index.

However, habitat dynamics was by far more complex than simple destruction of historical patches and resulted from a complex combination of destruction and creation of calcareous grassland patches (Fig. 2). In 1920, 96 calcareous grassland patches were evident in the study landscape and occupied a total area of 448 ha. Between 1920 and 1965, 36 (37.5\%) were lost. The 60 remaining patches suffered high fragmentation between 1920 and 1965 as they lost approximately half of their total area and were divided into 78 patches. However, in 1965, 117 new patches (a total area of $152 \mathrm{ha}$ ) were identified on cartographical documents, which were not present on the 1920 document. We suggest these patches originated from the creation of new calcareous grasslands between 1920 and 1965. However, due to the higher reliability of the 1965 GIS (use of aerial photographs), we cannot exclude the possibility that some patches interpreted as calcareous grasslands were already present in 1920, but were not mapped at that time. Therefore, the "new" status of these patches remains unconfirmed. Between 1965 and $2002,56 \%$ of the old patches (i.e. patches that were already present in 1920) were destroyed. Remaining old patches suffered tremendous fragmentation with a $73 \%$ reduction of total area 
and an $83 \%$ increase in patch number due to division. Patches created between 1920 and 1965 also suffered the same fragmentation pattern; and $38 \%$ of the patches, representing $44 \%$ of the total area, were lost between 1965 and 2002. The area of the remaining patches was reduced by $76 \%$ and division increased patch number by $38 \%$. However, during the $1965-2002$ period, we found the origin of 57 new patches for a total area of 9 ha. The target habitat dynamics evaluated over the past 90 years and within each time period shows a complex mix of new and old patches of different ages over the current landscape. From the total area of calcareous grasslands currently present, $57.6 \%$ were already present in 1920, $27.1 \%$ were created between 1920 and 1965, and 15.3\% were created between 1965 and 2002 .

\section{Extinction debt and colonization credit estimates}

We limited our estimates of colonization credit to patches that were created between 1965 and 2002 (i.e., patches less than 40 years old), due to the previously described uncertainty regarding the origin of new patches created between 1920 and 1965. 57 new patches were found between 1965 and 2002, and 17 were retained for credit colonization estimates; 35 were discarded because they occupied an area less than $0.052 \mathrm{ha}$. These patches were not suitable for comparisons with other groups of patches because comparably small patches were absent. Five new patches were eliminated because they were observed in sites that were calcareous grasslands in 1920, were absent in 1965 and re-appeared in 2002. Their "new patch"status was therefore tenuous. The total area covered by the 17 selected "new patches" was 8.02 ha (approximately 90\% of the area of new patches created between 1965 and 2002). The 17 patches (mean area: $0.472 \mathrm{ha}$, range: 0.052-2.778 ha) originated from the conversion of arable fields (four patches, $3.34 \mathrm{ha}$ ), clearing in forests (four patches, $2.41 \mathrm{ha}$ ) and creation of new road verges (nine patches, 2.27 ha). Forty-four "old patches" (mean area: 0.604 ha, range: 0.048 $2.794 \mathrm{ha}$ ) exhibiting a similar range of current area were retained for model comparisons.

Table 1: $P$-value regression between total species richness $\left(S_{\text {tot }}\right)$ and specialist species richness $\left(S_{s p}\right)$ and current area and connectivity. $(-)$ Indicates a negative relationship.

\begin{tabular}{cccc}
\hline Patch type & & Area & Connectivity \\
\hline \multirow{2}{*}{ Old patches $(n=44)$} & $S_{\text {tot }}$ & $<0.001$ & 0.161 \\
& $S_{\text {sp }}$ & 0.002 & 0.005 \\
\multirow{2}{*}{ New patches $(n=17)$} & $S_{\text {tot }}$ & 0.907 & $0.338(-)$ \\
& $S_{\text {sp }}$ & $0.849(-)$ & $0.344(-)$ \\
\hline
\end{tabular}


Species richness $\left(S_{\text {tot }}\right.$ and $S_{s p}$ ) was significantly related to the current area for "old patches" (Table 1). However, significant relationships were not detected between current species richness and current patch area for "new patches". The relationship between current patch connectivity and current species richness was only significant for specialist species in "old patches".

Table 2: Estimates and test for extinction debts (four first lines, differing in the choice of the area loss threshold for distinction between high loss and low loss patches) and colonization credits (three last lines). $n$ is the number of patches, m.l. is the mean area loss. Parallelism is the $p$-value of the interaction between current area and the low loss/high loss effect (extinction debt) or the new/old patches effect (colonization credit). Debt/Credit is the estimated extinction debt/colonization credit with the associated pvalue.

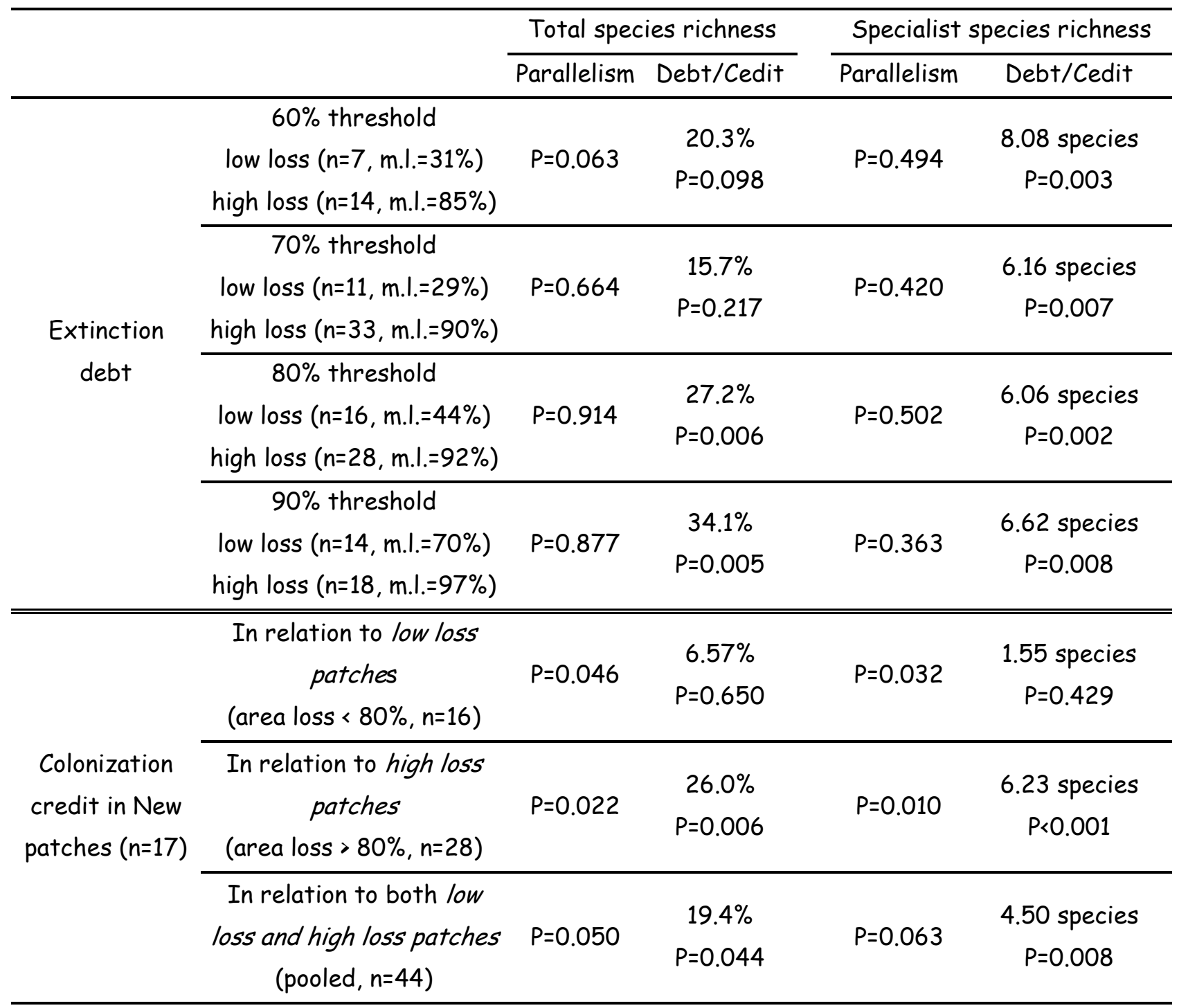


Parallelism of regression lines between the species richness-area models for "high loss old patches" and "low loss old patches" was accepted in all the cases for extinction debt estimates (Table 2). Specialist species extinction debt was significant for all area loss thresholds use to distinguish "low loss patches" and "high loss patches". Extinction debt for specialist species ranged from 8.08 species $(P=0.003)$ at the $60 \%$ area loss threshold to 6.06 species $(P=0.002)$ at the $80 \%$ area loss threshold (Table 2 ). The 6.06 specialist species value, in the case of the $80 \%$ threshold corresponds to approximately $35 \%$ of the mean specialist species richness for "high loss patches". Estimations of extinction debt for total species richness are given in percent (percent of species present in a patch) due to the log-transformation on this variable. For total species richness, extinction debt analysis was more sensitive regarding the selection for area loss threshold, ranging from $15.7 \%(P=0.217)$ at the $70 \%$ area loss threshold to $34.1 \%(P=0.005)$ at the $90 \%$ area loss threshold (Table 2). Extinction debt for total species richness was also significant at the $80 \%$ threshold ( $27.2 \%, P=0.006$, Table2). To elucidate the effect of the occurrence of an extinction debt on colonization credit estimates, we retained the $80 \%$ area loss threshold for distinction between "low loss old patches" and "high loss old patches", given the highest average (total and specialist species) p-values of extinction debt at this threshold. At this threshold, mean area losses in "low loss old patches" and "high loss old patches" were respectively $44 \%$ (SD=34\%) and $92 \%$ (SD=7\%). Parallelism between the species richness-area models for "new patches" and "low loss patches" or "high loss old patches" was rejected at the $5 \%$ significance level in all cases but one (specialist species, in relation to all "old patches", $P=0.063$ ) for the colonization credit estimates (Table 2). This absence of parallelism between regression lines for the different models is illustrated in Figure 3. A significant colonization credit was detected when "new patches" were compared to "high loss old patches" (colonization credit $=26.0 \%$ and 6.23 species for $S_{\text {tot }}$ and $S_{\text {sp }}$, respectively) or when new patches were compared to all "old patches", including "low loss old patches" and "high loss old patches" (colonization credit $=19.44 \%$ and 4.50 species for $S_{\text {tot }}$ and $S_{\text {sp }}$, respectively). The colonization credit detected when "new patches" were compared to "high loss patches" was almost equivalent to the extinction debt indicated for "high loss old patches" (27.2\% of total species richness, 6.06 specialist species). In contrast, no colonization credit was detected when "new patches" were compared to "low loss old patches". Colonization credit did not differ between patches with different origins (conversion of arable fields, clearing in forests and creation of new road verges), neither for specialist species richness $\left(F_{[2 ; 14]}=1.01, P=0.390\right)$, nor for total species richness $\left(F_{[2 ; 14]}=0.58, P=0.573\right)$. 

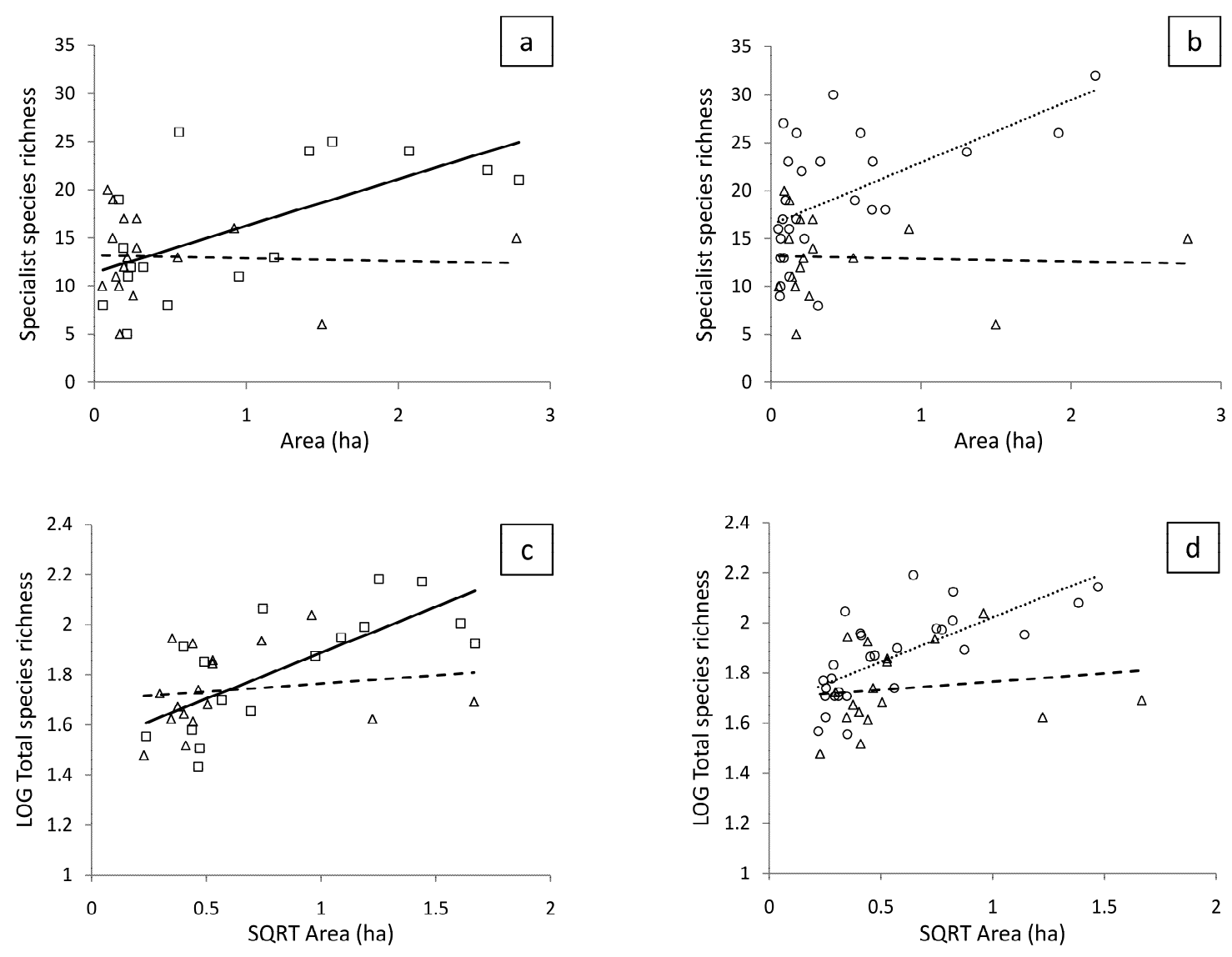

Fig. 3: Relationship between area and (a-b) total species richness and ( $c-d)$ specialist species richness for the three patch types. Variable transformations are those used for the ANCOVA analyses. Circles and dotted lines are high loss patches $(b-d)$, Squares and plain lines are low loss patches $(a-c)$. Triangles and dashed lines are new patches $(a-b-c-d)$.

DCA revealed that the species composition of "new patches" was comparable to other groups of patches (Fig. 4). The total species composition analysis (Fig. 4a) revealed that "new patches" were less represented and placed in the lower-right of the scatter plot, which corresponded to the presence of specialist species (e.g. Scabiosa columbaria, Helianthemum nummularium, and Thymus pulegioides). DCA based only on specialist species (Fig. 4b) and Fischer exact tests (Table 3 ) revealed that some species typical for short turf grasslands (e.g. Anthyllis vulneraria $(P=0.006)$, Festuca lemanii $(P=0.003)$ and Polygala comosa $(P=0.021))$ were significantly less represented in "new patches". 

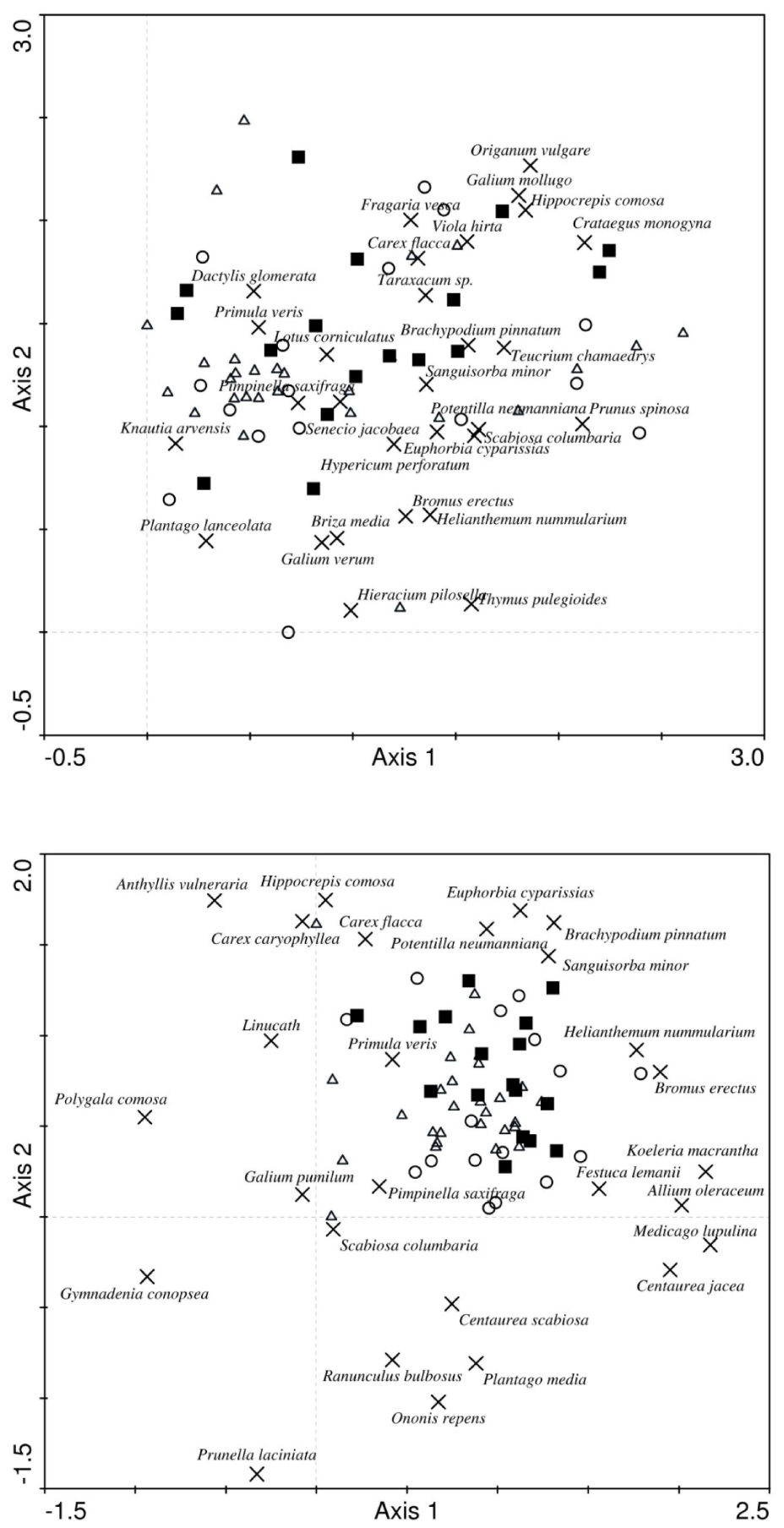

Fig. 4: Detrended correspondence analysis scatter plot of (a) total species composition and (b) specialist species composition. Triangles are high loss old patches, circles are low loss old patches and squares are new patches. Species with weight $>20 \%$ were plotted (crosses). 
Table 3: Relative occurrence of specialist species in old and new patches. $P$ is the $p$-values of the Fischer exact tests comparing relative occurrences.

\begin{tabular}{|c|c|c|c|}
\hline & $\begin{array}{c}\text { Old patches } \\
n=44\end{array}$ & $\begin{array}{c}\text { New patches } \\
n=17\end{array}$ & $P$ \\
\hline Allium oleraceum & 0.50 & 0.41 & 0.371 \\
\hline Anthyllis vulneraria & 0.41 & 0.06 & 0.006 \\
\hline Brachypodium pinnatum & 0.91 & 0.94 & 0.817 \\
\hline Bromus erectus & 0.89 & 0.88 & 0.637 \\
\hline Carex caryophyllea & 0.41 & 0.18 & 0.076 \\
\hline Carex flacca & 0.75 & 0.88 & 0.937 \\
\hline Carex tomentosa & 0.05 & 0.06 & 0.815 \\
\hline Carlina vulgaris & 0.16 & 0.00 & 0.088 \\
\hline Centaurea jacea & 0.55 & 0.47 & 0.405 \\
\hline Centaurea scabiosa & 0.57 & 0.47 & 0.344 \\
\hline Centaurium erythrea & 0.09 & 0.18 & 0.913 \\
\hline Cirsium acaule & 0.20 & 0.00 & 0.041 \\
\hline Euphorbia cyparissias & 0.93 & 0.76 & 0.087 \\
\hline Festuca lemanii & 0.66 & 0.24 & 0.003 \\
\hline Galium pumilum & 0.55 & 0.12 & 0.002 \\
\hline Gentianella ciliata & 0.11 & 0.06 & 0.460 \\
\hline Gentianella germanica & 0.14 & 0.12 & 0.607 \\
\hline Gymnadenia conopsea & 0.27 & 0.18 & 0.334 \\
\hline Helianthemum nummularium & 0.98 & 0.88 & 0.185 \\
\hline Himantoglossum hircinum & 0.07 & 0.00 & 0.368 \\
\hline Hippocrepis comosa & 0.59 & 0.59 & 0.604 \\
\hline Koeleria macrantha & 0.50 & 0.18 & 0.020 \\
\hline Koeleria pyramidata & 0.02 & 0.00 & 0.721 \\
\hline Linum catharticum & 0.61 & 0.35 & 0.061 \\
\hline Medicago lupulina & 0.39 & 0.53 & 0.903 \\
\hline Neotinea ustulata & 0.02 & 0.00 & 0.721 \\
\hline Onobrychis viciifolia & 0.07 & 0.06 & 0.692 \\
\hline Ononis repens & 0.52 & 0.35 & 0.183 \\
\hline Ophrys apifera & 0.02 & 0.00 & 0.721 \\
\hline Ophrys insectifera & 0.07 & 0.00 & 0.368 \\
\hline Orchis anthropophora & 0.02 & 0.00 & 0.721 \\
\hline Orchis militaris & 0.02 & 0.00 & 0.721 \\
\hline Pimpinella saxifraga & 0.80 & 0.65 & 0.189 \\
\hline Plantago media & 0.59 & 0.35 & 0.083 \\
\hline Polygala comosa & 0.34 & 0.06 & 0.021 \\
\hline Potentilla neumanniana & 0.84 & 0.71 & 0.200 \\
\hline Primula veris & 0.66 & 0.41 & 0.071 \\
\hline Prunella laciniata & 0.32 & 0.12 & 0.098 \\
\hline Ranunculus bulbosus & 0.52 & 0.24 & 0.039 \\
\hline Salvia pratensis & 0.02 & 0.00 & 0.721 \\
\hline Sanguisorba minor & 0.98 & 0.94 & 0.483 \\
\hline Scabiosa columbaria & 0.66 & 0.47 & 0.145 \\
\hline Thymus praecox & 0.02 & 0.00 & 0.721 \\
\hline Trifolium montanum & 0.16 & 0.18 & 0.717 \\
\hline
\end{tabular}




\section{DISCUSSION}

Studies of temporal dynamics in temperate, open, and semi-natural habitats have systematically addressed the general patterns of area decrease and isolation increase resulting from habitat fragmentation (Lindborg \& Eriksson 2004; Adriaens et al. 2006; Helm et al. 2006; Cristofoli et al. 2010a; Krauss et al. 2010). Little attention has been paid to the potential contribution of secondary habitat origins through time (but see Jacquemyn et al. 2003; ArroyoMora et al. 2004), although it may have strong implication in metatopulation functioning (Johst et al. 2002; Bossuyt \& Honnay 2006). Our work demonstrated that in our study landscape, spatial changes in calcareous grasslands resulted from two processes acting jointly: destruction and creation of habitat patches. As a result, target habitats are presently composed of a complex mix of new patches and old patches of different ages. However, the emergence of new patches was not adequate to counteract the fragmentation process. The current level of calcareous grassland fragmentation observed in the present study was among the highest reported in Europe (Krauss et al. 2010). The co-existence of historical fragmented and newly created patches colonized by grassland species may therefore lead to conditions of double disequilibrium regarding species richness: extinction debt and colonization credit.

In the present study, historical patches (>80 years old) represented only $32.6 \%$ of the number of patches currently in the landscape, but nonetheless represented a larger proportion (57.6\%) of the current habitat area. These historical patches represent core areas of the calcareous grassland ecological network. Our results indicated that historical patches have lost a high proportion of area and are not at equilibrium with their species richness compared to more stable patches. Consequently, these patches likely support an extinction debt indicated by an average excess of approximately $35 \%$ specialist species. This level of extinction debt was rather similar whatever the area loss threshold for distinction between "high loss patches" (that are supposed to exhibit an extinction debt) and "low loss patches" (that are supposed to be free of extinction debt and are therefore considered as a reference). The extinction debt results in our study site were therefore rather robust regarding methodology, as already shown in Piqueray et al. (2011b). Extinction debt, moreover, could have been underestimated in our study as "low loss patches" are likely not completely free of extinction debt. Extinction debt was already shown to occur in calcareous grassland landscapes (Lindborg \& Eriksson 2004; Helm et al. 2006). However, in other landscapes with similar levels of fragmentation, previous studies reported the absence of extinction debt (Adriaens et al. 2006; Cousins et al. 2007). The future payment of this extinction debt in the study landscape will most likely lead to the extinction of a proportion of the rarest specialists, and may also seriously affect the metapopulation of other specialists with a decrease in population numbers.

Colonization credit estimates in "new patches" differed with reference to historical patches. When habitat patches exhibiting an extinction debt ("high loss patches") were included 
in the analysis, a colonization credit was detected, leading to the conclusion that, on average "new patches" had not reached their final species richness. However, when historical "low loss patches" were used as a reference (the most likely to be at equilibrium), a colonization credit was not found within "new patches". New patches with different origins (conversion of arable fields, clearing in forests or creation of new road verges) did not exhibit different colonization credit, suggesting that species richness may recover equally whatever the origin of the patch creation. This result is particularly unexpected as calcareous grassland restoration from arable land was shown to be difficult without strong management such as topsoil removing and/or hay addition (Walker et al. 2004; Edwards et al. 2007; Kiehl \& Pfadenhauer 2007; Piqueray \& Mahy 2010). Moreover, Gibson and Brown (1992) showed that former arable grasslands still differ from ancient grasslands in their floristic composition after decades, which was not the case in our study. However, in this study, we only surveyed presence/absence of species. Therefore, we cannot exclude that small grassland refugia (e.g. at the border of former arable fields) had a strong influence on the data and on the results. A lack of colonization credit was also found by Cristofoli et al. (2010b) in new patches of another semi-natural temperate habitat: wet heathlands. This pattern sharply differs with results found for woodlands where colonization credit may persist for more than one century (Vellend et al. 2006).

In practice, the identification of an extinction debt calls for management programs that include habitat restoration. Species richness is one of the indicators often used to assess restoration success; therefore the possible extinction debt should be taken into account in restoration surveys. In restoration ecology, it is widely accepted that restoration success should be assessed in comparison with a reference ecosystem (Holl \& Cairns 2002). The choice of an appropriate reference ecosystem is of major importance as it determines the goals for a restoration program. Our results highlight the dangers in using habitats exhibiting an extinction debt as reference habitats for establishing milestones in restoration evaluation and success. However, a lack of colonization credit detected in newly created patches formerly not dedicated to directed restoration is all the more encouraging for future restoration programs. Our results were unexpected given the current fragmentation of calcareous grasslands in our study area. Increased level of habitat fragmentation typically prevents diaspore dispersal between isolated patches. It is worth noting that richness-area relationships were significantly different between "new patches" and "old patches". This was due to the fact that the largest "new patches" did not recover their definitive species richness, while smaller new patches recovered. In this context, we cannot conclude the complete absence of a colonization credit in all new patches. The nonsignificant area-richness relationship in "new patches" suggests that rate of colonization is independent of area. As a consequence, large patches that have to recover higher species richness might exhibit a colonization credit for a longer period of time.

However, restoration success cannot be assessed only on species richness (Mortimer et al. 1998; Kiehl et al. 2006). An ecosystem may be species-rich, but the species may not be representative of the reference community. We found that not only species richness, but also 
species composition was similar between "old patches" and "new patches". Only a few original species representative of the expected species composition occurred less in "new patches", notably those from short turf grasslands. This result was unexpected as many calcareous grassland species exhibit low dispersal abilities. Propagule availability is recognized as a major constraint for the restoration of these ecosystems (Hutchings \& Stewart 2002; Piqueray \& Mahy 2010). Before concluding to a potential success of calcareous grassland restoration within a lag time of less than 40 years, we should also take care that species assemblage may lead to the formation of communities with different structures and diversity. Piqueray et al. (2011a) have shown that, after restorative clear-cutting, typical grassland species colonized rapidly restored habitats, but community structure and evenness were not restored so quickly. Lacking data on species abundance in our habitat patches, we could not assess this topic in the present study.

\section{ACKNOWLEDGMENT}

This work was undertaken as part of the project "Development and test of a methodology for the elaboration of Natura 2000 sites designation acts", funded by the Walloon Public Service (DGARNE-DNF). This study was supported by the FRS-FNRS (contract FRFC 2.4556.05)

\section{REFERENCES}

Adriaens D., Honnay O., Hermy M. (2006). No evidence of a plant extinction debt in highly fragmented calcareous grasslands in Belgium. Biol. Conserv. 133: 212-224.

Arroyo-Mora J.P., Sánchez-Azefeifa G.A., Rivard B., Calvo J.C., Janzen D.H. (2004). Dynamics in landscape structure and composition for the Chorotega region, Costa Rica from1960 to 2000. Agr. Ecosyst. Environ. 106: 27-39.

Baudry J., Tatoni T. (1993). Changes in landscape patterns and vegetation dynamics in Provence, France. Landscape Urban Plan. 24: 153-159.

Bisteau E., Mahy G. (2005). Vegetation and seed bank in a calcareous grassland restored from a Pinus forest. Appl. Veg. Sci. 8: 167-174.

Bizoux J.P., Brevers F., Meerts P., Graitson E., Mahy G. (2004). Ecology and conservation of Belgian populations of Viola calaminaria, a metallophyte with a restricted geographic distribution. Belg. J. Bot. 137: 91-104.

Bossuyt B., Honnay O. (2006). Interactions between plant life span, seed dispersal capacity and fecundity determine metapopulation viability in a dynamic landscape. Landscape Ecol. 21: 1195-1205.

Cousins S.A.O. (2009). Extinction debt in fragmented grasslands: paid or not? J. Veg. Sci. 20: 3-7.

Cousins S.A.O., Ohlson H., Eriksson O. (2007). Effects of historical and present fragmentation on plant species diversity in semi-natural grasslands in Swedish rural landscapes. Landscape Ecol. 22: 723-730.

Cristofoli S., Mahy G. (2010). Colonisation credit in recent wet heathland butterfly communities. Insect Conserv. Divers. 3: 83-91.

Cristofoli S., Monty A., Mahy G. (2010a). Historical landscape structure affects plant species richness in wet heathlands with complex landscape dynamics Landscape Urban Plan. 98: 92-98.

Cristofoli S., Piqueray J., Dufrêne M., Bizoux J.P., Mahy G. (2010b). Colonization credit in restored wet heathlands. Restor. Ecol. 18: 645-655. 
Delescaille L.M. (2002). Nature conservation and pastoralism in Wallonia. Pages 39-52 in Redecker B., Finck P., Härdtle W., Riecken U., Schröder E., eds. Pasture landscapes and nature conservation. Berlin: Springer-Verlag.

Edwards A.R., Mortimer S.R., Lawson C.S., Westbury D.B., Harris S.J., Woodcock B.A., Brown V.K. (2007). Hay strewing, brush harvesting of seed and soil disturbance as tools for the enhancement of botanical diversity in grasslands. Biol. Conserv. 134: 372-382.

Fagan K.C., Pywell R.F., Bullock J.M., Marrs R.H. (2008). Do restored calcareous grasslands on former arable fields resemble ancient targets? The effect of time, methods and environment on outcomes. J. Appl. Ecol. 45: 1293-1303.

Faucon M.P., Parmentier I., Colinet G., Mahy G., Luhembwe M.N., Meerts P. (2009). May Rare Metallophytes Benefit from Disturbed Soils Following Mining Activity? The Case of the Crepidorhopalon tenuis in Katanga (D. R. Congo). Restor. Ecol.: In Press.

Gibson C.W.D., Brown V.K. (1992). Grazing and vegetation change: deflected or modified succession? J. Appl. Ecol. 29: 120-131.

Hanski I. (1994). A practical model of metapopulation dynamics. J. Anim. Ecol. 63: 151-162.

Hanski I., Ovaskainen O. (2002). Extinction debt at extinction threshold. Conserv. Biol. 16: 666-673.

Helm A., Hanski I., Pärtel M. (2006). Slow response of plant species richness to habitat loss and fragmentation. Ecol. Lett. 9: 72-77.

Holl K.D., Cairns J. (2002). Monitoring and appraisal. Pages 409-432 in Perrow M.R., Davy A.J., eds. Handbook of ecological restoration. Principles of restoration. Cambridge: Cambridge University Press.

Holling C.S. (1973). Resilience and stability of ecological systems. Ann. Rev. Ecol. Evol. Syst. 4: 1-23.

Hutchings M.J., Stewart A.J.A. (2002). Calcareous grasslands. Pages 419-442 in Perrow M.R., Davy A.J., eds. Handbook of ecological restoration. Restoration in practice. Cambridge: Cambridge University Press.

Jackson S.T., Sax D.F. (2009). Balancing biodiversity in a changing environment: extinction debt, immigration credit and species turnover. Trends Ecol. Evol. 25: 153-159.

Jacquemyn H., Butaye J., Hermy M. (2003). Influence of environmental and spatial variables on regional distribution of forest plant species in a fragmented and changing landscape. Ecography 26: 768-776.

Johst K., Brandl R., Eber S. (2002). Metapopulation persistence in dynamic landscapes: the role of dispersal distance. Oikos 98: 263-270.

Jongman R.H.G. (2002). Homogenization and fragmentation of the European landscape: ecological consequences and solutions. Landscape Urban Plan. 58: 211-221.

Jongman R.H.G., Pungetti G., eds. (2004). Ecological networks and greenways: concept, design, implementation Cambridge, UK: Cambridge University Press. 345 p.

Kiefer S., Poschlod P. (1996). Restoration of fallow or afforested calcareous grassland by clearcutting. Pages 209-218 in Settele J., Margules C.R., Poschlod P., Henle K., eds. Species survival in fragmented landscapes. The Netherlands: Kluwer academics publishers.

Kiehl K., Pfadenhauer J. (2007). Establishment and persistence of target species in newly created calcareous grasslands on former arable fields. Plant Ecol. 189: 31-48.

Kiehl K., Thormann A., Pfadenhauer J. (2006). Evaluation of initial restoration measures during the restoration of calcareous grasslands on former arable fields. Restor. Ecol. 14: 148-156.

Krauss J., et al. (2010). Habitat fragmentation causes immediate and time-delayed biodiversity loss at different trophic levels. Ecol. Lett. 13: 597-605.

Krüger A.M., Hellwig F.H., Oberprieler C. (2002). Genetic diversity in natural and anthropogenic inland populations of salt-tolerant plants: random amplified polymorphic DNA analyses of Aster tripolium L. (Compositae) and Salicornia ramosissima Woods (Chenopodiaceae). Mol. Ecol. 11: 1647-1655.

Kuussaari M., et al. (2009). Extinction debt: a challenge for biodiversity conservation. Trends Ecol. Evol. 24: 564-571. 
Lambinon J., Delvosalle L., Duvigneaud J. (2004). Nouvelle flore de Belgique, du Grand-Duché de Luxembourg, du Nord de la France et des régions voisines. Meise: Jardin botanique national de Belgique. $p$.

Laurance W.F. (2008). Theory meets reality: how habitat fragmentation research has transcended island biogeographic theory. Biol. Conserv. 141: 1731-1744.

Lindborg R. (2007). Evaluating the distribution of plant life-history traits in relation to current and historical landscape configurations. J. Ecol. 95: 555-564.

Lindborg R., Eriksson O. (2004). Historical landscape connectivity affects present plant species diversity. Ecology 85: 1840-1845.

Moilanen A., Nieminen M. (2002). Simple connectivity measures in spatial ecology. Ecology 83: 11311145.

Mortimer S.R., Hollier J.A., Brown V.K. (1998). Interactions between plant and insect diversity in the restoration of lowland calcareous grasslands in southern Britain. Appl. Veg. Sci. 1: 101-114.

Palm R. 2002. Macros Minitab pour la régression linéaire. (15th December 2008 2008; http://www.fsagx.ac.be/si/reglin/accueil.htm)

Pärtel M., Kalamees R., Zobel M., Rosén E. (1998). Restoration of species-rich limestone grassland communities from overgrown land: the importance of propagule availability. Ecol. Eng. 10: 275-286.

Perry G. (2002). Landscapes, space and equilibrium: shifting viewpoints. Prog. Phys. Geog. 26: 339359.

Piqueray J., Mahy G. (2010). Revue bibliographique sur la restauration des pelouses calcicoles en Europe : contraintes rencontrées et solutions proposées. Biotechnol. Agron. Soc. Environ. 14: 471-484.

Piqueray J., Bisteau E., Bottin G., Mahy G. (2007). Plant communities and species richness of the calcareous grasslands in southeast Belgium. Belg. J. Bot. 140: 157-173.

Piqueray J., Bottin G., Delescaille L.M., Bisteau E., Colinet G., Mahy G. (2011a). Rapid restoration of a species-rich ecosystem assessed from soil and vegetation indicators: the case of calcareous grasslands restored from forest stands. Ecol. Indic. 11: 724-733.

Piqueray J., Bisteau E., Cristofoli S., Palm R., Poschlod P., Mahy G. (2011b). Plant species extinction debt in a temperate biodiversity hotspot: Community, species and functional traits approaches. Biol. Conserv.: In press.

Poschlod P., WallisDeVries M.F. (2002). The historical and socioeconomic perspective of calcareous grasslands: lessons from the distant and recent past. Biol. Conserv. 104: 361-376.

Prendergast J.R., Quinn R.M., Lawton J.H., Eversham B.C., Gibbons D.W. (1993). Rare species, the coincidence of diversity hotspots and conservation strategies. Nature 365: 335-337.

Ricklefs R.E. (2004). A comprehensive framework for global patterns in biodiversity. Ecol. Lett. 7: 115.

Saunders D.A., Hobbs J.A., Margules C.R. (1991). Biological consequences of ecosystem fragmentation : a review. Conserv. Biol. 5: 18-32.

ter Braak C.F.J., Smilauer P. (2002). CANOCO reference manual and CanoDraw for Windows user's Guide: software for canonical community ordination (version 4.5). Ithoca, NY, USA: Microcomputer Power. 500 p.

Turner M.G. (2010). Disturbance and landscape dynamics in a changing world. Ecology 91: 28332849.

Turner M.G., Gardner R.H., O'Neill R.V. (2001). Landscape ecology in theory and practice: pattern and process. New York, USA: Springer-Verlag. p.

Vellend M., Verheyen K., Jacquemyn H., Kolb A., Van Calster H., Peterken G., Hermy M. (2006). Extinction debt of forest plants persits for more than a century following habitat fragmentation. Ecology 87: 542-548.

Walker K.J., Stevens P.A., Stevens D.P., Mountford J.O., Manchester S.J., Pywell R.F. (2004). The restoration and re-creation of species-rich lowland grassland on land formerly managed for intensive agriculture in the UK. Biol. Conserv. 119: 1-18. 
WallisDeVries M.F., Poschlod P., Willems J.H. (2002). Challenges for the conservation of calcareous grasslands in northwestern Europe: integrating the requirements of flora and fauna. Biol. Conserv. 104: 265-273. 